\title{
SUHTLUSSTRATEEGIAD JA -TAKTIKAD MÜÜGIVESTLUSTES
}

\author{
Liina Eskor
}

Ülevaade. Artiklis antakse ülevaade Tartu Ülikooli Eesti dialoogikorpuse ühe osa, müügivestluste struktuurist ja müüja poolt kasutatavatest strateegiatest oma eesmärgi täitmisel. Tutvustatakse ka arutluspõhist suhtlustaktikate käsitlust ning vaadeldakse, millises ulatuses on võimalik seda müügivestluste peal rakendada."

Võtmesõnad: korpuslingvistika, dialoogikorpus, korpuse märgendamine, müügivestlus, suhtlusstrateegia, arutluspõhine suhtlustaktika, eesti keel

\section{Sissejuhatus}

Käesolevas artiklis on vaatluse all müügivestlused ja neis esinevad suhtlusstrateegiad. Müügivestlused sisaldavad koolitusfirma töötajate kõnesid loodetavatele klientidele (s.t omavahel suhtlevad ametiisikud). Müügiagendi eesmärgiks on info kogumine kliendi kohta, kursuste vastu huvi tekitamine, ostusoovi korral argumenteerimine või kui see pole vajalik, siis ostuotsusele kaasa aitamine (pikemalt müügivestluste kohta vt Kasterpalu 2006). Artiklil on kaks eesmärki. Esiteks püütakse välja tuua analüüsitud müügivestluste nn laiemad strateegiad. Nende abil on võimalik leida müügivestluste sisemine struktuur, s.t vaadelda, millistele suhtluslikele pidepunktidele toetub müüja kliendis huvi tekitamiseks (peatükk 3). Teiseks ülesandeks on vaadelda, mil määral ja kuidas on võimalik rakendada müügivestlustes arutluspõhiseid suhtlustaktikaid (peatükk 4). Nimetatud ülesanded on eeskuju ja innustust saanud Kristiina Jokineni suhtlusstrateegiate ideest konstruktiivse dialoogi juhtimise mudelis (peatükk 2.1) ning Tartu Ülikoolis arendatud arutluspõhisest suhtlusstrateegiate ja- taktikate käsitlusest (peatükk 2.2). Seni on eestikeelseid infodialooge (eraisikute kõned infotelefonile) analüüsitud K. Jokineni konstruktiivse dialoogi mudeli (Jokinen 1996a, 1996b) seisukohalt (Eskor 2004, 2005) ning vaadeldud ka suhtlusstrateegiate järjendeid ehk strateegiaid laiemas mõistes (Eskor 2006).

* Tööd on osaliselt toetanud Eesti Teadusfond (grant nr 5685). 
Käeoleva uurimuse tarbeks analüüsiti algselt 16 müügivestlust (vestlused, mis olid selleks ajaks dialoogiaktidega ${ }^{1}$ märgendatud ja ühestatud), kuid neist üheksas müügiteemalist vestlust ei arendatud (sest soovitud inimesega ei olnud võimalik rääkida). Seega pakkus sobivat analüüsimaterjali seitse müügivestlust. Kasutatud alamkorpuse suuruseks on 7792 sõna ehk 771 vooru.

Nii infodialoogid kui ka müügivestlused on osa Tartu Ülikooli Eesti dialoogikorpusest $(\mathrm{EDiK})^{2}$ ning näidetes on kasutatud vestlusanalüüsi transkriptsiooni. Korpus koosneb eri tüüpi institutsionaalsetest vestlustest ning on litereeritud ja dialoogiaktidega märgendatud. Korpuse loomise kaugemaks eesmärgiks on välja töötada kasutajaga loomulikus eesti keeles suhtlev dialoogsüsteem. Sellises süsteemis peaks arvuti oskama modelleerida inimese ajus toimuvaid protsesse: partneri jutu mõistmist, vastuse planeerimist ja ülesehitamist jms. Suhtlusstrateegiad võiksid aidata arvutil selles abiks olla.

\section{Suhtlusstrateegia ja -taktika mõiste}

\subsection{Suhtlusstrateegiad konstruktiivse dialoogi juhtimise mudelis}

Soome arvutilingvist Kristiina Jokinen on kasutanud suhtlusstrateegia mõistet konstruktiivse dialoogi juhtimise mudelis (Jokinen 1996a, 1996b). Mudel loodi kasutajale sobilike vastuste genereerimiseks infodialoogides ning selle lähtekohaks on kooperatiivse ja sidusa suhtluse aluseks olevad üldised suhtlusprintsiibid. Suhtlusprintsiibid on H. Paul Grice' i maksiimide täpsustused, s.t üldised põhimõtted, mille abil vestluses osalejad üksteise juttu mõistavad. P. Grice (1975) toob välja neli maksiimi: kvantiteedi-, kvaliteedi-, relevantsus- ja meetodimaksiim. K. Jokineni mudelis saab arvutiprogramm suhtlusprintsiipide toel valida sobiva suhtlusstrateegia ja lahendada nii (kasutaja abiga) oma andmebaasi puudujääke. Sobiva strateegia valik tähendab valikut dialoogi jätkamise eri võimaluste vahel (nt küsida kasutajalt infot juurde, soovitada muid võimalusi, paluda küsimust korrata jm). K. Jokineni lähenemise puhul valitakse sobiv strateegia igale lausungile, arvestades sealjuures nelja faktorit: lausungi ootuspärasust (eelneva lausungiga võrreldes), lausungi teemat (kas on/ei ole vestluse senise teemaga seotud), initsiatiivi (kas vestluse initsiatiiv on kõnelejal või partneril) ning vestluse eesmärki (kas on käesoleva lausungi ajaks täidetud või mitte). Dialoog, kus info küsijal on laiemas mõistes üks eesmärk (nt bussi väljumisaja teadasaamine), sisaldab endas tavaliselt ka mitut väiksemat eesmärki. Need tekitab vastaja oma täpsustavate küsimustega (küsimusele vastamiseks on tavaliselt tarvis üle küsida sihtjaama, nädalapäeva vms). Järgnevalt on toodud näide kõnest infotelefonile, kus on märgendatud lausungitele vastavad dialoogiaktid (Eesti dialoogiaktide tüpoloogia järgi, trükitähtedes, vt Hennoste, Rääbis 2004) ning suhtlusstrateegiad (Jokineni järgi, kaldkirjas, vt Jokinen 1996a). Helistajat tähistab $H$ ja infotelefonil vastajat $V$.

(1)

$\mathrm{H}$ : kas 'telefoninumbrid mis algavad numbritega viis 'kaks, (.) kas need on 'Rakvere või: 'Pajusti omad. KYE: ALTERNATIIV, TVE: PAKKUMINE finish/start 
V: $\{-\}($.$) tähendab (.) vaatan? KYJ: EDASILÜKKAMINE, TVJ: VASTU-$ VÕTMINE notrelated

(22.0) no 'Pajustis akkavad numbrid viis 'seitse=aga: (0.5) Rakvere::s (.) ma nüüd ei 'näe=et viis 'kaks päris oleksid=aga KYJ: ALTERNATIIV: EITAV follow-up-old

$\mathrm{H}$ : ahah VR: NEUTRAALNE INFO OSUTAMINE UUEKS somethingelse aga võibola see siin on mingi 'muu koha number lihtsalt. SEE: ARVAMUS new dialogue

Helistaja küsimus infotelefoni töötajale on alternatiivküsimus, samuti on see esitatud pakkumisena vestluse teema vahetamiseks (esitatud näide on lõik vestluse keskelt). Sellistele tingimustele vastab strateegia finish/start ('eelmine lõpetatud, alusta uuega'), s.t selline küsimus on oodatud, vestluse teemaga seotud, küsimuse esitamise ajaks on vestluse varasemad eesmärgid täidetud ning initsiatiiv on kõnelejal (s.t helistajal). Vastaja on teema vahetamisega nõus, kuid info otsimiseks vajab ta pisut aega, seetõttu lükkab ta vastamise edasi. Sellise lausungi saab märgendada strateegiaga notrelated ('teemaga sidumata'): lausung ei ole partnerile ootuspärane (ta ootab vastust), see ei ole vestluse teemaga otseselt seotud, vestluse eesmärk on lausungi ajaks täitmata (vastust ei ole ju veel antud) ning initsiatiiv on vastajal. Sellele järgnebki vastus. Kuna helistaja küsimus oli esitatud alternatiivküsimusena, on nüüd tegemist alternatiivvastusega. Kumbki pakutud alternatiiv pole õige, aga kolmandat varianti siiski ei pakuta. Strateegiaks on siin follow-up-old ('jätka eelmisega'): vastus kui selline on oodatud, see on teemaga seotud, vestluse eesmärk on selle lausungi ajaks veel täitmata (kuigi just parajasti täitmisel) ning initsiatiiv on endiselt vastajal. Helistaja järgmine lausung ( $a h a h$ ) on vabatahtlik reaktsioon, saadud info on uus. Sobiv strateegia on siin somethingelse ('muu'), s.t antud lausung ei ole vestluse kontekstis otseselt ootuspärane (kuna see on lihtsalt helistaja reaktsioon, millele mingit reageeringut ei oodata), samas on ta eelneva lausungiga seotud (reageering eelnevale) ning ka vestluse eesmärk on selleks hetkeks juba täidetud. Initsiatiiv on partneril (s.t tegemist ei ole küsimusega). Järgneb helistaja seisukohavõtt, täpsemalt arvamus, mis on tähistatud strateegiaga new dialogue (uus dialoog). See ei ole otseselt oodatud, samas on teemaga seotud ning ka vestluse eesmärk on täidetud. Helistaja on nüüd kõneleja rollis (s.t ta ootab seisukohavõtule infotöötaja reaktsiooni).

\subsection{Suhtlusstrateegiad ja -taktikad arutluspõhises dialoogimudelis}

Tartu Ülikoolis on loodud dialoogimudel, mis kaasab arutlusmudeli (Koit 1996, Õim 1996, Koit, Õim 2003). Selle kohaselt reguleerivad inimese (praegusel juhul kliendi) arutlust selle üle, kas teha või jätta tegemata mingi tegevus D, kolme liiki faktorid: sisemised ehk subjektiivsed faktorid soov ja vajadus ning väline faktor kohustus (Koit 1996: 99-114, Koit, Õim 2003: 721-735). Subjekt soovib teha tegevust D, kui D meeldivad küljed ületavad ebameeldivad. Subjektil on vaja teha D, kui D tegemise kasu on suurem kui kahju. Subjekt on sunnitud/kohustatud tegema D, kui D tegemata jätmine toob kaasa karistuse. Püüdes jõuda selgusele, kas teha D või mitte, lähtub inimene kõigepealt soovist (s.t kas tegevuse meeldivad küljed 
ületavad ebameeldivad). Kui see nii on, siis kontrollitakse vahendite olemasolu. Kui vahendid on olemas, kaalutakse tegevuse $\mathrm{D}$ muid positiivseid ja negatiivseid külgi (kasulikkust ja kahjulikkust). Kui D on keelatud tegevus, kaalutakse ka tegemisele järgnevat karistust. Kui head küljed ületavad summaarselt halvad, siis on arutluse tulemuseks otsus teha tegevus D, vastupidisel juhul otsus jätta D tegemata. Sellises mudelis on tarvis kokku liita nimetatud aspektide (meeldivus, ebameeldivus, kahjulikkus jt) kaalud, s.t kaaludel peaksid olema arvulised väärtused. Kuigi reaalsuses seda muidugi ei tehta, võib siiski kõik omadussõnad, mida nt meeldivate ja ebameeldivate tegevuste kirjeldamisel kasutatakse, teatud skaalale paigutada ning saada niimoodi vastava aspekti kaalu arvulise väärtuse (Koit, Õim 2003: 726).

Arutleva subjekti motivatsioonisfääri mudeliks on kaalude vektor $\mathrm{k}=$ (k(ressursid), k(meeldiv), k(ebameeldiv), k(kasulik), k(kahjulik), k(kohustuslik),

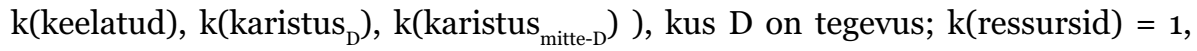
kui subjekt omab kõik vajalikud ressursid tegevuse D tegemiseks (vastasel korral o); $\mathrm{k}$ (kohustuslik) $=1$, kui D on subjekti jaoks kohustuslik (vastasel korral o); $\mathrm{k}($ keelatud) $=1$, kui $\mathrm{D}$ tegemine on subjekti jaoks keelatud (vastasel korral o). Ülejäänud kaalude väärtusteks on mittenegatiivsed täisarvud.

Suhtlemise reeglid võtab arutluspõhises dialoogimudelis kokku suhtlusstrateegia. See on algoritm, mida osaleja kasutab oma suhtluseesmärgi saavutamiseks. Strateegia rakendamiseks võib sõltuvalt olukorrast kasutada erinevaid suhtlustaktikaid, nt partneri ahvatlemine, veenmine, ähvardamine. Lähtudes üle-eelmises lõigus sõnastatud tegevusi reguleerivatest faktoritest, rõhutab vestluses osaleja (müügivestlustes mü̈̈ja) ahvatlemise puhul partnerile tegevuse meeldivust, veenmise puhul kasulikkust ja ähvardamise puhul tegevuse tegematajätmisele järgnevat karistust. Suhtlustaktika valik sõltub väga paljudest asjaoludest, kõige üldisemalt saab need jagada kaheks: müüja subjektiivsed aspektid (meeleolu, isikuomadused) ja objektiivsed aspektid. Siin peetakse silmas suhtlust kui sotsiaalset nähtust ning konkreetsemalt selle erinevaid parameetreid, nt kas suhtlus on koostöine või vaenutsev, isiklik või isikupäratu (tavaliselt ametikõnelus), milline on suhtluskaugus (kas suhtlevad sõbrad või ülemus ja alluv), milline on suhtlemise toon (sõbralik või ebasõbralik) (Koit, Õim 2003: 728).

Müügidialooge analüüsides ilmnevad konkreetsed olukorrad, kus nimetatud taktikaid rakendatakse. Näitena võib tuua veenmise taktika: autor A, partner B, tegevus D: A tahab, et B teeks D (Koit 1996: 104).

1) Kui B vastus on "ei", " $k$ (kasulik) väike", " $k$ (kohustuslik) $)=0$ ", " $k$ (meeldiv)väike", siis esitada vastuargument kaalu $\mathrm{k}(\mathrm{kasulik})$ suurendamiseks.

2) Kui B vastus on " $k$ (ressursid $)=O$ ", siis näidata ressursside olemasolu või nende hankimise võimalust.

3) Kui B vastus on "k(kahjulik) suur", siis esitada argument kaalu $\mathrm{k}(\mathrm{kahjulik)} \mathrm{vähendamiseks.}$

4) Kui B vastus on " $k$ (kohustuslik) $=1$ ja $k$ (karistus) mitte-D väike", siis esitada argument kaalu $\mathrm{k}($ karistus mitte-D) suurendamiseks.

5) Kui B vastus on " $k$ (keelatud) ja k(karistus D) suur", siis esitada argument kaalu $\mathrm{k}($ karistus $\mathrm{D})$ vähendamiseks.

6) Kui B vastus on "k(ebameeldiv) suur", siis esitada argument kaalu k(ebameeldiv) vähendamiseks. 


\section{Müügivestluste struktuur suhtlusstrateegiate kaudu}

Käesolev peatükk annab ülevaate müügivestluste struktuurist. Kuigi K. Jokineni suhtlusstrateegiad on loodud kasutamiseks infodialoogides ja müügivestluste jaoks need eriti hästi ei sobi (kuna siin ei ole suhtluse eesmärgiks info andmine ja saamine, vaid koolituskursuste tutvustamine ja/või müük), püütakse siin K. Jokinenist innustust saades leida müügivestlustest strateegiaid (kui dialoogiaktide järjendeid), mis kulgevad läbi mitme vooru ning annavad kokkuvõttes ülevaate vestluste struktuurist. Siin pakutud müügivestluste struktuur strateegiate järjendina on selline:

- sissejuhatus ja täpsustamine;

- osavõtlikkus;

- veenmine;

- lähenemine teisest küljest;

- nõustumine kliendiga;

- kontakt tulevikuks.

Järgnevalt on dialoogide osad esitatud strateegiana (strateegia nimi kaldkirjas) ning ka dialoogiaktide järjendina. Sulgudes olevad aktid võivad konkreetsest vestlusest puududa.

\subsection{Sissejuhatus ja täpsustamine}

Sissejuhatusega algab müügivestluste sisuline osa (koolituse pakkumine). Sellele eelnevaid vestluse algusrituaale, identifitseerimist ja viisakusküsimusi on kirjeldanud R. Kasterpalu (2006). Üldjuhul on sissejuhatuseks müüja küsimus (nn taustauuring) firma suuruse, koolitusvajaduse, tulevikuplaanide jms kohta (2). Sissejuhatus võib olla esitatud ka väitena (3).

(2)

M: kuidas see juhatuse (.) otsus nüd `otsustus.| KYE: AVATUD |

K: ee `noh me `rääkisime sellest `pikalt hh | KYJ: INFO ANDMINE |

M: [jaa?] | VR: NEUTRAALNE JÄTKAJA |

K: [rääkisime] sellest pikalt jah=aga me ei jõudnudki `kokkuleppele et=kas meil: `on vaja või `ei. | KYJ: INFO PUUDUMINE |

Aktijärjendina ${ }^{3}$ :

M: KYE: AVATUD/ JUTUSTAV KAS/ SULETUD KAS

K: KYJ: JAH/ INFO ANDMINE/ INFO PUUDUMINE/ KEELDUMINE/ EI

(3)

M: .hh me oleme teiega sin `rääkinud `koolituse `teemadel. | SEE: VÄIDE |

K: [jaa?] | SEJ: NÕUSTUMINE |

M: [mitmeidki] kordi. | IL: TÄPSUSTAMINE |

Aktijärjendina:

M: SEE: VÄIDE

K: SEJ: NÕUSTUMINE

(M: IL: TÄPSUSTAMINE)

${ }^{3}$ Aktijärjendid siin ja edaspidi kirjeldavad kõiki sarnaseid situatsioone, mitte ainult eelnenud näidet. Sulgudes esitatud 
Sissejuhatusega samasuguse struktuuri ja sisuga vestlust leidub ka dialoogi keskel, siis on see tähistatud müüja strateegiaga täpsustamine:

(4)

M: kuidas teil muidu plaanis `on kas jääbki (.) `kolm inimest müügi peale või või tulevikus ka (.) `laiendada (.) peaks müük [`suurenema] | KYE: AVATUD |

K: [tändab] see `laieneb ainult võibolla siis `oma:: `jae`müügi: `võrgu:: [ee] | KYJ: INFO ANDMINE |

\subsection{Osavõtlikkus}

Osavõtlikkust on eristatud kolmel korral. Müüja näitab omaalgatuslikult, et ta mõistab klienti. Osavõtlikkust võib väljendada vastust pakkuva küsimusega (5) või ka arvamuse avaldamisega (6).

(5)

M: no siis ma kujutan ette=et praegu on tõesti `väga=väga kiire `aeg vist.

| KYE: VASTUST PAKKUV |

K: mhmh. | KYJ: JAH |

(.) tuleb tõdeda. | KYJ: JAH |

M: \$ jah. \$ | VR: NEUTRAALNE VASTUVÕTUTEADE |

Aktijärjendina:

M: KYE: VASTUST PAKKUV

K: KYJ: JAH

(M: VR: NEUTRAALNE VASTUVÕTUTEADE)

(6)

M: .hh st ma kujutan ette kui nüüd ee (.) pood `lahti läheb või tähendab mitte `kaubamaja vabandust läheb lahti nüüd (.) detsembri`kuus ja=ja (.) mt ja see `jõulud ja see `kiire aeg `mööda läheb, (0.5) .hh ja hakkab see `kevad pihta ja hakkab selline nüd juba väike ru `tiin tekkima=et mis on see `töö=ja=ja mis on vaja seal 'töö juures `teha, [.hh] | SEE: ARVAMUS |

K: [tähendap,] (o.5) me `tahaksime `tegelikult kui me (.) mingit `koolitust `tahaksime siis `enne`kõike tahaksime me `müüjatele seda `teha. | SEJ: MUU |

Aktijärjendina:

M: SEE: ARVAMUS

K: SEJ: NÕUSTUMINE/ MUU

(M: VR: NEUTRAALNE VASTUVÕTUTEADE) 


\subsection{Veenmine}

Veenmist võib vaadelda argumentide vahetamisena. Järgnevalt müüja poolt kasutatud argumente.

- Koolituse kasulikkus kliendile. Näiteks: koolitus aitab rutiini peletada, koolituse abil saab firma teavet ja oskusi, mille abil oma maine konkurentidest kõrgemale tõsta. Koolitus on lõdvestav, aitab kogemusi vahetada.

- Sobivate koolituste läbiviimise kord ja sisu. Näiteks: klient on enda arvates sobiliku kursuse välja valinud, kuid tema usutlemisel avastab müüja, et kliendile sobiks hoopis teine kursus, ja annab sellest teada.

- Koolituse sisu ja toimumisaja muutmine vastavalt kliendi vajadustele. Näiteks pakub müüja kursust, mis kliendi arvates on mõeldud algajaile ja seega talle ei sobi. Müüja teatab, et teemasid võib muuta ja täiendada.

- Koolitusel saadud teadmisi saab uutele töötajatele edasi anda, nii et juba katseajal oleks uutest inimestest müügitöös rohkem abi.

Kuigi vestluste lõpuks soovib müüja teada konkreetset aega, millal uuesti kliendile helistada, selgitab ta, et konkreetse koolituse valik on väga oluline ning selleks on tarvis aega. Kuna müüja ei soovigi nende vestluste käigus ühtegi konkreetset kokkulepet sõlmida, võib järeldada, et ta täitis oma eesmärgi, s.t sai kursusi tutvustada ja ennast meelde tuletada. Müüja saavutas kõigis vestlustes kokkuleppe, et võtab kliendiga mõne aja pärast jälle ühendust. Ükski klient ei keeldunud sellest.

Veenmine dialoogiaktide järjendina tähendab müüja poolt tüüpiliselt aktide DIE: PAKKUMINE või DIE: ETTEPANEK kasutamist (7). Lisaks sellele võib müüja kasutada ka erinevaid seisukohavõtte, nt SEE: VÄIDE (8), SEE: ARVAMUS (9), samuti info andmist üksikaktina (10).

(7)

M: .h et=et kui nüd (.) ee 'teie kontigenti 'vaadata sis võibola (.) võibola seal kui 'teemasid natukene (o.2) e seles mõtes täiendada 'muuta et=et võtta midagi `sellist asja `sisse mida nüd `algajatele `päris EI (.) ole mõtet ‘pakkuda. | DIE: PAKKUMINE |

K: jah. | DIJ: NÕUSTUMINE |

M: .h midagi lisamüügi=[mm] ’lisamüügi sarnast `kaupluses | DIE: PAKKUMINE |

K: [jah.] | DIJ: NÕUSTUMINE |

Aktijärjendina:

M: DIE: PAKKUMINE/ ETTEPANEK

(K: VR: NEUTRAALNE JÄTKAJA)

(M: IL: SELETAMINE)

K: DIJ: NÕUSTUMINE/ PIIRATUD NÕUSTUMINE

(M: IL: SELETAMINE/ TÄPSUSTAMINE)

(8)

M: ja ja `samas siis kui tuleb see `uus inimene kes hakkab ak`tiivse müügiga tegelema (.) näiteks .h sis `sellisel puhul tal on .h `praegusel inimesel `on `kogemus nendest `toodetest ja kogemus `firmast=et e siis ta saab anda neid 
`teadmisi edasi ka .h ka `uuele inimesele et see juba `katseajal saaks .h saaks `tõesti sellist ee `eesmärgipärast `müügitööd teha. | SEE: VÄIDE |

$\mathrm{K}:$ mhmh? | SEJ: PIIRATUD NÕUSTUMINE |

Aktijärjendina:

SEE: VÄIDE

SEJ: PIIRATUD NÕUSTUMINE/ NÕUSTUMINE/ MUU

(9)

M: .hh aga (o.8) mt nojah `seles mõts=et `kui ta läheb ka edasi ütleme sinna `kauplusesse võetakse uus `müügi `mees siis .hh ma usun=et `kindlasti `need ‘teadmised mis tal on sellisest `müügist ja kliendi `mõjutamisest kuluvad `marjaks `ära ka sealsamas `kaupluses. | SEE: ARVAMUS |

K: ee ma ei vaidle `vastu. | SEJ: NÕUSTUMINE |

Aktijärjendina:

M: SEE: ARVAMUS

K: SEJ: NÕUSTUMINE

(10)

M: .h aga=aga=jah (0.5) seles mõttes `küll=et kui `jah vanad olijad mõtlevad `tõesti et=et see on=ee `sellisele: ütleme `uuele (.) `uuele `inimesele `rohkem mõeldud sis sis seda `irmu ei tohiks. $\mathrm{h}$ ja $=\mathrm{uh}$ `olla iseenesest et $=\mathrm{et} \mathrm{se}=\mathrm{on}$ $>$ selline küllaltki < ja kui teda on vel nädala 'vahetusele panna ja kokku viia mingisuguse firma `sisese. $\mathrm{h}$ sellise mõnusa `õhtu veetmisega=et=siss ta on: noh pigem `lõdvestav ja=ja (.) sad `oma kogemusi: 'välja rääkida ‘töökogemusi=aga teistelt (.) teistelt `uusi kogemusi=ja .h teatud `situatsioone `arutada ja leida [võbola] | YA: INFO ANDMINE |

\subsection{Lähenemine teisest küljest}

Kui klient ei ole koolitusest huvitatud (või ta näiteks ei oska öelda, kas tema firma võiks tulevikus koolitust tellida), püüab müüja läheneda teisest küljest ja vestlust edasi arendada. Selleks kasutab ta akte KYE: AVATUD (11, rida 2) või KYE: VASTUST PAKKUV (12, rida 2).

(11)

1. K: ‘teema on: 'lahtine. | IL: KOKKUVÕTMINE | (0.8)

2. M: jaa:.| VR: NEUTRAALNE VASTUVÕTUTEADE |

.h ee kuidas o:lid `lood nende `referentsidega: kas [ee] | KYE: AVATUD | 3. K: [eõ]õ [`sain] `kätte selle: mm:: (1.0) `noh selle `muu=te=es=er selle [`Akutrelli] | KYJ: INFO ANDMINE |

(12)

1. K: ma nüd hheh hetkel jälle `öelda et mul on juba `plaanid `tehtud ma e:i söendaks paraku .hh `järje `kordselt. | KYJ: INFO PUUDUMINE | 2. M: * mhmh. * | VR: NEUTRAALNE VASTUVÕTUTEADE | .hh no õõ (.) võobla=t tõesti üks asi on sellised 'kirjalikud ‘plaanid õõ 
`graafikutena `paika `panna=aga .h aga=ilmselt sellised `mõtted `plaanide tasandil `peas on ol- on siiski [`olemas.] | KYE: VASTUST PAKKUV |

3. K: [on=on.] |KYJ: JAH |

Aktijärjendina:

M: KYE: AVATUD/ VASTUST PAKKUV

$\mathrm{K}$ : KYJ: INFO ANDMINE/ JAH

\subsection{Nõustumine kliendiga}

Kui klient avaldab millegi kohta arvamust (tihti aktidega SEE: VÄIDE või DIE: ETTEPANEK), siis müüja alati nõustub kliendiga, kasutades akte SEJ: NÕUSTUMINE, (13); DIJ: NÕUSTUMINE (14). Analüüsitud dialoogides ei vaielnud müüja kunagi kliendile vastu.

(13)

K: ja ainult ei ole jutt (.) müügist (.) sest 'müük on `müük on üks osa. | SEE: VÄIDE |

M: ja müügi- on loomu- loomu 'likult üks [osa.] | SEJ: NÕUSTUMINE |

Aktijärjendina:

K: SEE: VÄIDE

M: SEJ: NÕUSTUMINE

(14)

K: [et] leida mingi::d siuksed pool ’pühad või ma ei tea mis sin tulemas `on \{üldse\} | DIE: ETTEPANEK |

M: jah. | DIJ: NÕUSTUMINE |

no seda on võimalik iseenesest ka: ka noh 'Tiritamme poolt ka alati 'riigipühadel `teha et see ei ole [nagu] ee puirav | DIJ: NÕUSTUMINE |

Aktijärjendina:

K: DIE: ETTEPANEK

M: DIJ: NÕUSTUMINE

\subsection{Kontakt tulevikuks}

Kontakt tulevikuks tähistab vestluse lõpuosa, kus üks osalejatest pakub välja uue suhtluse aja. Strateegia võib algatada nii müüja kui klient. Müüja algatust esines kolmes vestluses, nt (15) ja (16), kliendi algatust neljas vestluses, nt (17). Strateegia on vormistatud küsimuse ja vastuse järjendina.

(15)

M: .h ee ja: ja `millal oleks `minul otstarbekas uuesti ühendust `võtta sel teemal

| KYE: AVATUD |

et äkki san ka `ise `aidata kuidagi `kaasa teie otsuse kujunemisele. | DIE: PAKKUMINE |

(o.8) kas [midagi lähemalt] | YA: MUU | 
K: [teeks äkki] ee `selle kuu: ütleme pealt kahe`kümendal. | KYJ: INFO ANDMINE | | DIE: ETTEPANEK |

M: mt (.) no `teeme `nii? | DIJ: NÕUSTUMINE |

Aktijärjendina:

M: KYE: AVATUD

K: KYJ: INFO PUUDUMINE + DIE: PAKKUMINE

M: DIJ: NÕUSTUMINE

(16)

M: mhmh. | VR: NEUTRAALNE VASTUVÕTUTEADE |

.hh nii=et võtan teiega ühendust kolmeteistkümnendal `jaanuaril? | DIE: PAKKUMINE |

ja räägime juba sis kokku `saamisest, (.) millal [võiks] | DIE: ETTEPANEK |

K: [täitsa] `nõus. | DIJ: NÕUSTUMINE |

Aktijärjendina:

M: DIE: ETTEPANEK

K: DIJ: NÕUSTUMINE

(17)

K: `lepiksime `nimodi `kokku et=ee `kui ma nüüd olen ära `otsustanud ['kas] ma | DIE: PAKKUMINE |

M: [ ${ }^{*} \mathrm{mhmh}^{*}$ ] | VR: NEUTRAALNE JÄTKAJA |

K: tulen `ise või saadan `müügimehe [tähendab] ee ma `helistan teile `tagasi. | DIE: PAKKUMINE |

M: [ ${ }^{*} \mathrm{mhmh}^{*}$ ] | VR: NEUTRAALNE JÄTKAJA |

(o.2)

M: mt jaa. | DIJ: NÕUSTUMINE |

Aktijärjendina:

K: DIE: PAKKUMINE

M: VR: NEUTRAALNE JÄTKAJA

M: DIJ: NÕUSTUMINE

Käesolevas peatükis käsitletud nn laiemad strateegiad kirjeldavad müügivestluste üldist struktuuri. Strateegiad võib jagada nende esinemiskoha järgi kaheks: strateegiad, mis võivad esineda ükskõik millises vestluse osas (täpsustamine, osavõtlikkus, veenmine, nõustumine kliendiga ja lähenemine teisest küljest), ning strateegiad, millel on kindel asukoht (sissejuhatus - vestluse alguses, kontakt tulevikuks - vestluse lõpus). Strateegiaid saab eristada ka nende esinemissageduse järgi: iga vestluse juurde kuuluvad sissejuhatus, veenmine, nõustumine kliendiga ja kontakt tulevikuks. Osavõtlikkust ja lähenemist teisest küljest igast müügivestlusest ei leia.

\section{Suhtlustaktikad müügivestlustes}

Järgnevalt vaadeldakse, milliseid suhtlustaktikaid (vt eespool 2.2) on võimalik leida müügivestlustest. Kuna müügivestlustes osalejad peavad jääma anonüümseks, siis ei saa käesolevas artiklis kahjuks avaldada neljast kõnevoorust pikemaid näiteid. 
Seega ei ole võimalik müüja suhtlustaktikate kasutamist täiel määral demonstreerida, kuid loodetavasti annavad ka lühemad dialoogilõigud asjast ülevaate.

Näidetes (18) ja (19) veenab müüja klienti koolitusel osalema. Klient esitab vastuväiteid ning müüja püüab teda veenda koolituse vajalikkuses. Klient väidab, et tema poe töötajad ei ole nõus koolitusele minema, kuna nad on juba vanad profid (rida 1), s.t esitab argumendi $k$ (kasulik) väike. Selle peale püüab müüja suurendada k(kasulik) kaalu argumentidega inimeste tundma õppimine, vaheldus ja huvitavad ülesanded (rida 4).

(18)

1. K: ütsid=nimodi=et=ee (.) kui sa (.) mind (.) `müüjate `kursustele tahad `saata sis ma võin sulle öelda et ma: sinna ei `lähe eksju=noh. | YA: INFO ANDMINE |

2. M: a 'haa. | VR: NEUTRAALNE INFO OSUTAMINE UUEKS |

3. K: hehe | YA: MUU |

4. M: \$ tegelikult \$ j(h)ah, se on küllaltki `huvitav `lähenemine nad nad ise saaksid `küllaltki `palju sealt `juurde. | SEE: VÄIDE |

tändap $=\mathrm{se}=\mathrm{on}=$ noh .h et kui kogu `firmaga seal `olla $=\mathrm{ja}=\mathrm{ja}$ : sab ää noh teises `situatsiooniski oma `oma inimesi rohkem `tundma ja=ja se on `vaheldus=ja seal on `huvitavaid `ülesanded mida nad lahendama peavad `koos=ja .h | SEE: VÄIDE |

Näites (19) kasutab müüja ahvatlemise taktikat (rida 1), suurendades $k$ (meeldiv) kaalu argumentidega mõnus õhtu, lõdvestus, kogemuste vahetamine. Sellele klient vastuargumente ei esita.

(19)

1. M: .h aga=aga=jah (0.5) seles mõttes `küll=et kui `jah vanad olijad mõtlevad `tõesti et=et see on=ee `sellisele: ütleme `uuele (.) `uuele `inimesele ‘rohkem mõeldud sis sis seda `irmu ei tohiks .h ja $=u$ h `olla iseenesest et=et $\mathrm{se}=$ on > selline küllaltki $<$ ja kui teda on vel nädala `vahetusele panna ja kokku viia mingisuguse firma `sisese .h sellise mõnusa `õhtu veetmisega=et=siss ta on: noh pigem `lõdvestav ja=ja (.) sad `oma kogemusi: ‘välja rääkida ‘töökogemusi=aga teistelt (.) teistelt `uusi kogemusi=ja .h teatud `situatsioone ‘arutada ja leida [võbola] | YA: INFO ANDMINE |

2. K: [mhmh] | VR: NEUTRAALNE JÄTKAJA |

3. M: paremad | YA: INFO ANDMINE |

4. K: [ \{ah soo te $\}$ | YA: PRAAK |

Näites (20) esitab müüja argumendid hea suhtumine klienti, maine tõstmine, kursus aitab eesmärki saavutada kaalu k(kasulik) suurendamiseks, s.t ta näitab siin samuti koolituse tellimise kasulikke aspekte (read 1 ja 3).

(20)

1. M: (.) ja ja kui nüüd `seal panna=nüd=ee `paika need ee (.) `inimeste=õ̃ ‘nimese `suhtumine teie `kaubamajasse=et et $=$ see $=$ on < 'väga: (.) `hea `suhtumisega .hh `klienti > selline `virma=sis ma kujutan ette=et `see loob ka väga jah `tõepoolest `väga `head .hh `võimalused õõ (.) tõsta see `maine oopis `kõrgemale kui nüd teie `konkurendid Pärnus.| SEE: ARVAMUS | .hh |YA: MUU | 
2. K: just nimelt. | SEJ: NÕUSTUMINE |

(0.5) see ongi `eesmärk. | SEJ: NÕUSTUMINE |

3. M: jah? | VR: NEUTRAALNE VASTUVÕTUTEADE |

et see $=$ on `kindlasti `suur `abi sellest > `kursustest oleks `just nimelt selle (o.8) `eesmärgi saavutamisel, < kindla`sti üks võibolla isegi `peamisi SEE: ARVAMUS |

Lõpetuseks veel näiteid, kuidas müüja kasutab erinevaid argumente rõhutamaks kliendile tegevusest saadavat kasu (iga näite juures on märgitud müüja konkreetne argument).

(21)

argument: koolitusel saadavad teadmised on igas olukorras kasulikud M: .hh aga (o.8) mt nojah `seles mõts=et `kui ta läheb ka edasi ütleme sinna `kauplusesse võetakse uus `müügi `mees siis .hh ma usun=et `kindlasti `need 'teadmised mis tal on sellisest `müügist ja kliendi `mõjutamisest kuluvad `marjaks `ära ka sealsamas `kaupluses.| SEE: ARVAMUS |

(22)

argument: võimalus saada toetusraha

M: sis ma kujutan `ette ku me `hakkame nüüd=nüüd `talvel kohe sellest ‘rääkima ja=ja asju `plaane tegema sis me võime sealt saada POOL summast sellest mis `tegelikult maksma läheb. | YA: INFO ANDMINE |

(23)

argument: koolituse sisu on võimalik kliendile sobivamaks muuta

M: .h et=et kui nüd (.) ee 'teie kontigenti 'vaadata sis võibola (.) võibola seal kui 'teemasid natukene (o.2) e seles mõtes täiendada 'muuta et=et võtta midagi `sellist asja `sisse mida nüd `algajatele `päris EI (.) ole mõtet 'pakkuda. | DIE: PAKKUMINE |

(24)

argument: koolitatud töötaja saab uusi töötajaid koolitada

M: ja ja `samas siis kui tuleb see `uus inimene kes hakkab ak`tiivse müügiga tegelema (.) näiteks .h sis `sellisel puhul tal on .h `praegusel inimesel `on ‘kogemus nendest `toodetest ja kogemus `firmast=et e siis ta saab anda neid ‘teadmisi edasi ka .h ka `uuele inimesele et see juba `katseajal saaks .h saaks `tõesti sellist ee `eesmärgipärast `müügitööd teha. | SEE: VÄIDE |

(25)

argument: head kursused

M: (o.8) sest=et jah `juhtimine on ju `Tiritammes päris `põhjalikult `esindatud seal `koolituse osas ja seal on kah `erinevad (.) .hh `erinevad 'võimalused. |YA: INFO ANDMINE|

Algne ettekujutus ja ootus, et müügivestlustes leidub lisaks veenmisele ka vähemalt samapalju näiteid ahvatlemise taktika kasutamise kohta, ei täitunud. Ahvatlemist, s.t tegevuse meeldivuse rõhutamist, kasutas müüja väga vähe. Muidugi võib mõne näite juures tekkida küsimus, et kas tegemist on veenmise või ahvatlemisega, sest millegi kasulikkuse näitamine võib muuta selle ka meeldivaks. Nii et veenmine ja ahvatlemine ei ole täiesti eraldiseisvad ega teineteist välistavad. 


\section{Kokkuvõtteks}

Artikli alguses seati ülesandeks kahe küsimuse lahendamine. Kõigepealt kavandati vaadelda müügivestluste struktuuri, et näha, millistele suhtluslikele pidepunktidele ehk strateegiatele toetub müüja kliendis huvi tekitamiseks. Müügivestluste analüüsi järel võib vestlustes esile tuua kuus strateegiat: sissejuhatus ja täpsustamine, osavõtlikkus, veenmine, lähenemine teisest küljest, nõustumine kliendiga, kontakt tulevikuks. Neist igaühes kasutab müüja mitmesuguseid võtteid kliendi tähelepanu püüdmiseks. Strateegiad jagunesid esinemiskoha järgi kaheks: strateegiad, mis võivad esineda ükskõik millises vestluse osas (täpsustamine, osavõtlikkus, veenmine, nõustumine kliendiga ja lähenemine teisest küljest), ning strateegiad, millel on kindel asukoht (sissejuhatus vestluse alguses, kontakt tulevikuks vestluse lõpus). Esinemissageduse järgi jagunesid strateegiad samuti kaheks: iga vestluse juurde kuuluvad sissejuhatus, veenmine, nõustumine kliendiga ja kontakt tulevikuks. Osavõtlikkust ja lähenemist teisest küljest igast müügivestlusest ei leia. Nimetatud strateegiate abil püüdis müüja koolituste vastu huvi tekitada, et klient ikka sooviks neist osa võtta. Müüja ülesandeks on märgata iga kliendi n-ö huvisähvatust ning sellest kinni haarata. Müüja veenab klienti koolituse vajalikkuses, esitades selleks erinevaid argumente. Ta ei vaidle kunagi kliendile vastu, on abivalmis ja vastutulelik, nagu müüja olema peab.

Teiseks analüüsiti, mil määral ja kuidas on müügivestlustes võimalik rakendada arutluspõhiseid suhtlustaktikaid. Müügivestlustele oli iseloomulik, et kliendid ei olnud eriti huvitatud koolituse tellimisest. Neil puudus selleks soov ja enda arvates ka vajadus. Kliendi otsust vestluse lõpuks mõjutas aga müüja. Oluliseks sai, kuidas müüja suutis näidata, et kliendil vajadus koolituse järele ikkagi on. Vajaduse väljaselgitamisel sai klienti juba edasi mõjutada ja loota, et kliendis tekib seepeale ka soov. Suhtlustaktikate seisukohalt oli analüüsitud vestlustes müüja põhiliseks mõjutusvahendiks kliendi veenmine, s.t tegevuse kasulikkuse rõhutamine. Veenmist saab vaadelda argumenteerimisena: müüja esitab kliendis huvi tekitamiseks erinevaid argumente. Müüja argumendid rõhuvad enamasti just tegevuse kasulikkusele. Samas näitas analüüs, et nii mõnegi argumendi puhul ei ole alati võimalik öelda, kas rõhutatakse tegevuse kasulikkust või kasutatakse hoopis ahvatlemise taktikat ja näidatakse tegevuse meeldivaid külgi. Kuna esitatud analüüsi aluseks on ainult seitse dialoogi, ei pruugi siin esitatu kehtida kõikide müügivestluste puhul. Praeguste väidete kinnitamiseks või ümberlükkamiseks peaks nimetatud vestlustaktikate esinemist kontrollima kindlasti kogu müügivestluste korpuses.

\section{Kirjandus}

Eskor, Liina 2004. Dialoogiaktid ja suhtlusstrateegiad: Eesti dialoogikorpuse analüüs. Magistritöö Tartu Ülikooli üldkeeleteaduse õppetoolis. Tartu.

Eskor, Liina 2005. Dialoogiaktid ja suhtlusstrateegiad: Eesti dialoogikorpuse analüüs. - Keel ja Kirjandus 9, 711-727.

Eskor, Liina 2006. Suhtlusstrateegiad infodialoogides. - Mare Koit, Renate Pajusalu, Haldur Õim (toim.). Keel ja arvuti. Tartu Ülikooli üldkeeleteaduse õppetooli toimetised 6. Tartu: Tartu Ülikooli Kirjastus, 183-195.

Grice, Paul 1975. Logic and Conversation. - D. Davidson and G. Harman (Eds.). The Logic of Grammar. Encino, CA: Dickenson, 64-75. 
Hennoste, Tiit; Rääbis, Andriela 2004. Dialoogiaktid Eesti infodialoogides: tüpoloogia ja analüüs. Tartu Ülikooli arvutiteaduse instituut. Tartu: Tartu Ülikooli Kirjastus.

Jokinen, Kristiina 1996a. Cooperative response planning in CDM. Reasoning about communicative strategies. - Proceedings of the 11th Twente Workshop on Language Technology: Dialogue Management in Natural Language Processing Systems. Twente, The Netherlands, 159-168. http://www.mlab.uiah.fi/ kjokinen/papers/199606TWEN. PDF (06.12.2006).

Jokinen, Kristiina 1996b. Goal formulation based on communicative principles. - Proceedings of the International Conference on Computational Linguistics. COLING-96. Copenhagen, Denmark, 598-603.

http://www.mlab.uiah.fi/ kjokinen/papers/199608COLI.PDF (o6.12.2006).

Kasterpalu, Riina 2006. Algusrituaalid müügikõnedes. - Mare Koit, Renate Pajusalu, Haldur Õim (toim.). Keel ja arvuti. Tartu Ülikooli üldkeeleteaduse õppetooli toimetised 6. Tartu: Tartu Ülikooli Kirjastus, 156-169.

Koit, Mare 1996. Implementing a dialogue model on the computer. - Haldur Õim (Ed.). Estonian in the Changing World. University of Tartu, Departement of General Linguistics. Tartu: University of Tartu, 99-114.

Koit, Mare; Õim, Haldur 2003. Eestikeelse dialoogi modelleerimine. - Keel ja Kirjandus 10, 721-735.

Õim, Haldur 1996. Naive theories and communicative competense: Reasoning in communication. - Haldur Õim (Ed.). Estonian in the Changing World. University of Tartu, Departement of General Linguistics. Tartu: University of Tartu, 211-231.

Liina Eskor (Tartu Ülikool) on erialalt arvutilingvist, tegeleb suulise keele uurimisega.

liina.eskor@ut.ee 


\section{COMMUNICATIVE STRATEGIES \\ AND TACTICS IN TELEMARKETING CALLS}

\section{Liina Eskor}

University of Tartu

In telemarketing calls communication takes place between business representatives on a win-win basis, which means that the caller is offering a competence (supposedly) needed by the receiver. The calls may have been addressed to top leaders of bigger Estonian companies. The original material for the present study consisted of 16 calls. However, only seven of them provided appropriate for the study as nine calls ended before ever reaching the marketing stage (for absence of the right person on the receiver end). The subcorpus analysed contained 7792 words used in 771 turns.

The calls are part of the Estonian dialogue corpus (EDiK) maintained at the University of Tartu. The transcription system used is typical for conversation analysis. The article points out some broader conversational strategies, which last through several turns. Following those strategies helps to find out the internal structure of the calls, i.e. to disclose how exactly the caller attempts to arouse interest at the other end of the line. As was proved by the dialogues analysed typical telemarketing calls consist of the following phases: introduction and specification, kind attention, persuasion, approach from another aspect, agreeing with the client, establishing contacts for the future.

Keywords: corpus linguistics, dialogue corpus, corpus annotation, telemarketing calls, communicative strategy, communicative tactics based on reasoning, Estonian 